\title{
What principles should govern the use of managed entry agreements?
}

\author{
Marianne Klemp, Katrine B. Frønsdal \\ Norwegian Knowledge Centre for the Health Services \\ Karen Facey on behalf of the HTAi Policy Forum \\ University of Glasgow
}

Background: To ensure rapid access to new potentially beneficial health technologies, obtain best value for money, and ensure affordability, healthcare payers are adopting a range of innovative reimbursement approaches that may be called Managed Entry Agreements (MEAs).

Methods: The Health Technology Assessment International (HTAi) Policy Forum sought to identify why MEAs might be used, issues associated with implementation and develop principles for their use. A 2-day deliberative workshop discussed key papers, members' experiences, and collectively addressed four policy questions that resulted in this study. Results: MEAs are used to give access to new technologies where traditional reimbursement is deemed inappropriate. Three different forms of MEAs have been identified: management of budget impact, management of uncertainty relating to clinical and/or cost-effectiveness, and management of utilization to optimize performance. The rationale for using these approaches and their advantages and disadvantages differ. However, all forms of MEA should take the form of a formal written agreement among stakeholders, clearly identifying the rationale for the agreement, aspects to be assessed, methods of data collection and review, and the criteria for ending the agreement.

Conclusions: MEAs should only be used when HTA identifies issues or concerns about key outcomes and/or costs and/or organizational/budget impacts that are material to a reimbursement decision. They provide patient access and can be useful to manage technology diffusion and optimize use. However, they are administratively complex and may be difficult to negotiate and their effectiveness has yet to be evaluated.

Keywords: (MeSH) Insurance, Health, Reimbursement, Reimbursement mechanisms, Technology assessment, Biomedical, Treatment outcome

Health technology assessment (HTA) users need to respond to the challenging economic climate and find new ways to

We thank Chris Henshall, Lou Garrison, Steven Pearson, Janet Hiller, and members of the HTAi Policy Forum (see Supplementary Table 1) for their contribution to this article, and HTAi for funding this work. support delivery of best value to all stakeholders. This might be achieved through Managed Entry Agreements (MEAs), which support new forms of reimbursement. However, despite the growing use of such Agreements, little has been published about their advantages and disadvantages or principles for their use. 
There is increasing recognition among all stakeholders that patients should be given rapid access to innovative technologies that address unmet medical needs and provide value for money (10). Over recent years healthcare budgets have increased, at a much higher rate than inflation, to meet demand and improve the quality of care. However, it is likely that these increases in healthcare budgets will reduce in real terms, with more stringent efficiency targets and more transparent processes for prioritizing technologies that can deliver demonstrable improvements in the quality of care and best value. Similarly, for industry, the costs of technology development have continued to increase over the past decade $(1 ; 15)$ creating a need to streamline technology development programs to demonstrate value to all decision makers. Alongside this, there is the complex world of technology pricing, where the list price of a medicine in one jurisdiction may be used as a "reference" to set the price in another and where the price of devices can be agreed at a hospital, regional, or country level. However, the listed price may not reflect the actual price arising from negotiations to reduce the total cost of technology use in the original jurisdiction (e.g., provision of a volume discount).

To meet the call for rapid access to innovative technologies, reimbursement decisions determining value are now being made immediately after licensing. For many reimbursement organizations, value is a function of clinical and cost-effectiveness. However, this is not a straightforward quantitative assessment, as a variety of judgments and assumptions are required to determine value. It is necessary to generalize controlled trials of efficacy to provide estimates of clinical effectiveness in a real-world setting (including extrapolation of short-term or surrogate endpoints to relevant clinical outcomes) and quantify costs over the lifetime of the disease. As a result, there are often concerns about whether promising, new, and expensive technologies will deliver their anticipated health gains in a real world setting and are best value.

Traditionally, reimbursement decisions have fallen into one of three categories: "yes", "no", or "yes, but with restriction" (e.g., use only after failing other therapies or in certain patient groups). To overcome the tension between funding new but expensive technologies and obtaining value for money, healthcare payers are increasingly adopting innovative reimbursement approaches. These reimbursement mechanisms have been given many names, such as risk sharing, coverage with evidence development (CED), access with evidence development (AED) (13), and payment for outcomes or performance-based reimbursement schemes (5). These are all forms of MEAs between manufacturers and payers which allow the technology to enter the market, the actual utilization or performance of the product to be tracked in a clearly specified patient population, and in some cases the level of reimbursement to be tied in some way to an outcome. If the technology does not perform to expectation, utilization, or budget impact, as agreed in advance between manufac- turer and payer, both parties share the risk. A recent review identified twenty-nine different forms of such agreements in Europe, North America, and Australasia (18), but they noted that it was not possible to assess the effectiveness of these agreements in meeting their objectives. Hence, the Health Technology Assessment International (HTAi) Policy Forum sought to identify the advantages and disadvantages of such agreements, issues associated with their implementation and to develop principles for their use.

\section{METHODS}

As a key meeting place for senior professionals working at the interface of HTA and decision making, the annual HTAi Policy Forum meeting was held in February 2010. The HTAi Policy Forum included twelve not-for-profit members (health service payers/providers or HTA-related organizations) and fourteen For-Profit members (pharmaceutical and device industries). Each sent two participants to this annual 2-day meeting, and they were joined by HTAi Board members and HTAi Board observers, who also participated fully in the meeting. The complete list of participants is included in Supplementary Table 1, which can be viewed online at www.journals.cambridge.org/thc2011005. All participants were involved in the scoping process before the meeting, in debates and workshops at the meeting, and reviewed this study.

The 2-day deliberative workshop discussed key papers (listed in Supplementary Table 2, which can be viewed online at www.journals.cambridge.org/thc2011005), members' experiences, and collectively addressed the following four key questions: (i) How do we define Managed Entry Agreements?; (ii) Why do manufacturers and payers enter into Managed Entry Agreements?; (iii) What are the advantages and disadvantages of Managed Entry Agreements for manufacturers, patients and payers?; (iv) What principles should govern the use of Managed Entry Agreements?

This study was developed by means of email and finalized at a post-workshop meeting in June 2010 attended by HTAi Policy Forum members and HTAi Board members. The opinions expressed in this study are believed to present a fair reflection of the exchanges of views. However, neither all participants, nor their affiliates necessarily agree with the entire content, for which the authors take full responsibility.

\section{RESULTS}

\section{Incentives for Establishing a MEA}

Definition. A definition of performance-based reimbursement schemes has been presented by Carlson et al. (5). This was used during the Policy Forum meeting as a basis for developing a definition of such schemes that suited the policy context and which we call "Managed Entry Agreements": 
A Managed Entry Agreement is an arrangement between a manufacturer and payer/provider that enables access to (coverage/ reimbursement of) a health technology subject to specified conditions. These arrangements can use a variety of mechanisms to address uncertainty about the performance of technologies or to manage the adoption of technologies in order to maximize effective their use, or limit their budget impact.

Categories of MEAs. MEAs appear in different forms that can be characterized according to the nature of the concerns they are dealing with:

- Managing budget impact: management of the process of adoption to address concerns about budget impact (e.g., through capping total budget impact, discounting, limiting number of doses, free first cycle, etc.).

- Managing uncertainty relating to clinical and/or costeffectiveness: management of uncertainty relating to the clinical and cost-effectiveness in the long-term, in a real-world clinical setting (e.g., through CED).

- Managing utilization to optimize performance: management of delivery systems to plan technology diffusion to targeted patients/ or by means of particular delivery mechanisms (e.g., limitation of technology diffusion to appropriately trained practitioners).

Managing budget impact is a particularly important risk for payers and providers, whereas managing utilization to avoid misuse is an important goal for all stakeholders. When making reimbursement decisions, there may be several issues that drive the deliberative process, and so there may be overlap in these forms of MEAs.

Criteria for Using MEAs and Risk-Sharing. Table 1 presents the reasons why each form of MEA might be used.

All forms of MEA require a written agreement between manufacturers and payers/providers about the basis for the agreement, what will be measured, how it will be measured, and the duration of the agreement, or trigger for review. The Australian Government has developed a template for these agreements, which are called deeds (2). In addition, specific issues unique to each form of MEA will need to be addressed, and the concept of risk sharing will differ among the three categories of MEAs.

MEAs that are intended to manage budget impact need to consider the affordability to the health system in question, for example, linkage of volume, maximum number of doses or outcomes to payment, and how an information system may track the actual use and cumulative costs.

To manage uncertainty relating to clinical and/or costeffectiveness, principles for use of CED state that the key uncertainties in modeling (such as extrapolation, generalizability, or transferability) need to be identified by methods such as value of information (11) and it must be possible to measure the required outcomes in a real-world setting that meets the requirements of research governance. Then the manufacturer may have to reduce the price if the product does not demonstrate clinical and/or cost-effectiveness after CED, that is, risk sharing of product performance assuming that a higher price has been agreed for reimbursement, to be reviewed when the new evidence is delivered. Under this scenario, the "risk" is that the higher price is not realized. Conversely, a lower than requested price may be granted at time of reimbursement with the option of an increase when the new evidence is available.

Important criteria for using MEAs that aim to manage utilization to optimize performance require a clear marker of performance that does not have high intra-individual variability (3). Additionally, a delivery system to carefully plan technology diffusion and an information system to track process and/or outcomes, and/or ensure value in subpopulations is needed. With this form of agreement, better utilization of a product would secure increased skills of the interventionist and improve patient safety, that is, risk sharing of clinicians/product performance. In such a case, management of utilization would try to counteract variation in benefit/risk ratios across hospitals and among clinicians.

\section{Examples of MEAs}

These examples of MEAs were presented at the Policy Forum meeting. The first was given by a healthcare provider, the second two by manufacturers.

Managing Budget Impact. In 1994, the Saskatchewan Prescription Drug Plan and Merck \& Co, Inc. created an agreement about use of finasteride (Proscar) for 3 years. Finasteride, a drug indicated in the treatment of benign prostatic hypertrophy, was promoted by the manufacturer on the basis that it would save the health system money by decreasing the need for surgical procedures (9). The manufacturer agreed to refund the cost of the drug in situations where a patient receiving the drug subsequently proceeded to surgery. Patients had to have consistently taken the drug for at least 12 months and proceeded to surgery within 90 days after discontinuing finasteride.

Substantial effort was required to put the scheme in place both by the healthcare system and the manufacturer, with challenges at legal, administrative, communication, and resource levels. When considering the outcomes, the overall utilization was lower than projected because few patients met the criteria for treatment and progressed to surgery, so the payment of the public portion was minimal. A key lesson from this agreement was that the timeline to establish an MEA should run parallel to the reimbursement process to minimize delay. Furthermore, this MEA provided a foundation for future agreement templates and an expectation of accountability was established.

Managing Uncertainty Relating to Clinical and/or Cost-Effectiveness. Since 2008, various health authorities (NHS in England/Wales, PBAC in Australia, 
Klemp et al.

Table 1. Rationale for Choosing between the Three Forms of MEA

\begin{tabular}{ll}
\hline MEA & \multicolumn{1}{c}{ Rationale for use } \\
\hline $\begin{array}{l}\text { Managing budget impact } \\
\begin{array}{l}\text { Managing uncertainty relating to clinical and/or } \\
\text { cost-effectiveness }\end{array}\end{array}$ & $\begin{array}{l}\text { Affordability by health system } \\
\text { Generalizability and transferability to be demonstrated } \\
\text { Long-term outcomes need to be confirmed } \\
\text { Evidence that will influence decision making is not going to be gathered otherwise } \\
\text { Anticipated comparator coming to market }\end{array}$ \\
Managing utilization to optimize performance & $\begin{array}{l}\text { Delivery system needed to carefully plan technology diffusion } \\
\text { Single clear marker of utilization with low intra-patient variability available } \\
\text { Value in subpopulation to be proven }\end{array}$
\end{tabular}

Note. MEA, managed entry agreement.

CADTH in Canada) have made agreements with Novartis about reimbursement/coverage of ranibizumab (Lucentis). Ranibizumab is a treatment for patients with wet age-related macular degeneration to improve vision and prevent blindness. The product has been approved based on clinical trials and drug simulation modeling which demonstrated benefit using an "as needed" regimen (starting with 3 monthly injections and followed with subsequent injections when patients began to lose vision again) (16). The uncertainty relating to cost-effectiveness of ranibizumab consisted of the number of injections which were needed in real life. This MEA tried to link funding with the effort to collect further data (number of injections needed) which can be considered as CED, although it relates only to dose and not to the generation of any new evidence of outcomes.

The MEA faced some implementation issues and required clinical registries, which it was hoped would provide more information on real world dosing and resulting effectiveness to validate economic modeling assumptions underlying the arrangements. In most countries, relevant data were available from routine data sources. Where additional registries were launched, additional costs were incurred by data collection focusing on a "hard" endpoint (number of injections).

Managing Utilization. From 1997 to 2003, MEAs were made between hospitals across Canada and Johnson \& Johnson for patients undergoing angioplasty with a stent. The adoption of the stent was rapid, since using this device not only markedly decreased the number of cases with restenosis (from $33 \%$ to $15 \%$ ), but also reduced catheterization laboratory time, eliminated need for an on-call cardiac surgery teams, diverted surgical patients to the catheterization laboratory, and significantly reduced late night call backs (Ames D, personal communication). Unfortunately, these stents were not always able to reach the patients' lesions due to tortuous anatomy and because the balloon catheter that delivered the stent was stiff at the tip, thus making it difficult to reach distal lesions. In these cases, the stent and the delivery balloon on which it is mounted were wasted, adding a significant cost to the catheterization laboratory budget. The manufacturer's solution was to improve physicians' training by offering an accredited course combined with an MEA that offered a performance guarantee if the lesion was not crossed. The manufacturer agreed to replace the device at no charge, or in some cases reimburse the costs of the device.

This MEA on utilization of a device provided incentives for physicians to be trained, allowed a more controlled dissemination of new technologies, and submission of audiovisual demonstrations have provided a learning opportunity both for the manufacturer and physicians. However, it was challenging to set up different MEAs to suit each hospital and manage all these arrangements.

\section{Other Examples of MEAs}

Further examples of MEAs in England and Wales are provided in Box 3 by Briggs and co-authors (4) and in the United States by Mohr and Tunis (14). These show that MEAs have been used extensively with pharmaceuticals, but few have been used with devices.

\section{Advantages and Disadvantages of MEAs}

MEAs may be difficult to negotiate, require legal input and increase the bureaucracy for all stakeholders. The "system level characteristics" of such CED arrangements are described well by MacLeod and Mitton who stress the need for detailed governance procedures, including consideration of independence, data ownership, audit, transparency, and appeal (12).

Managing multiple agreements in a healthcare system or across healthcare providers could prove untenable for the payer/provider or manufacturer. Furthermore, once an agreement is arranged in one hospital, others may call for the same or different agreements, which would increase the burden of the manufacturer. On the other hand, if the provider is running several systems for different products, this may cause confusion. Overall, the advantages and disadvantages of MEAs differ depending on the stakeholder group, as outlined in Table 2 .

\section{Principles That Should Govern the Use of MEAs}

It is suggested that MEAs should only be used when HTA identifies issues or concerns that are material to a coverage decision, and traditional decisions for reimbursement 
Table 2. Advantages and Disadvantages of MEA from Different Perspectives

\begin{tabular}{|c|c|c|}
\hline Stakeholders & Advantages & Disadvantages \\
\hline Manufacturer & $\begin{array}{l}\text { Access to market for promising technologies } \\
\text { Best performance of product through targeted use }\end{array}$ & $\begin{array}{l}\text { Costs/bureaucracy required for implementation of } \\
\text { agreement } \\
\text { Payback/price reductions if pre-agreed outcomes are not } \\
\text { met } \\
\text { Limited access if budget cap is reached } \\
\text { Real-world clinical effectiveness of a technology could be } \\
\text { compared with comparators' effectiveness in controlled } \\
\text { trials }\end{array}$ \\
\hline Provider/Payer & $\begin{array}{l}\text { Provide the technology in such a way that it demonstrates } \\
\text { value } \\
\text { Provide early access for patients and share risk with } \\
\text { manufacturer if the product is not performing as agreed } \\
\text { Limit total budget impact } \\
\text { Build evidence base to resolve uncertainties }\end{array}$ & $\begin{array}{l}\text { Costs/bureaucracy required for implementation of } \\
\text { agreement } \\
\text { Duplication of schemes with lack of transparency } \\
\text { Managing multiple schemes in small providers } \\
\text { Possible need to withdraw technologies at the end of the } \\
\text { agreement/difficult to withdraw once in practice }\end{array}$ \\
\hline Patient/society & $\begin{array}{l}\text { Access to promising technologies thus permitting greater } \\
\text { choice or only possible treatment } \\
\text { Investment in innovation is promoted }\end{array}$ & $\begin{array}{l}\text { Barriers to participation in MEA (such as administration } \\
\text { in specialist center) } \\
\text { Risk that the product does not show the benefit that is } \\
\text { expected } \\
\text { Possible withdrawal of a technology at the end of the } \\
\text { agreement } \\
\text { Data protection issues } \\
\text { Other more robust research is not undertaken }\end{array}$ \\
\hline
\end{tabular}

Note. MEA, managed entry agreement.

have been deemed inappropriate. This might occur when there is a lack of consensus or important mitigating circumstances relating to the technology, such as conditions with unmet medical need or where there is a lack of other therapeutic options. This might include situations where the impact of the technology is likely to be "disruptive" (12), or where there are limited data on the clinical effectiveness or cost-effectiveness of an innovative technology or if there is an urgent policy imperative (e.g., development of a vaccine for an influenza strain with a potentially high mortality rate). In such situations, MEAs could be used when HTA identifies concerns or issues about key outcomes and/or costs and/or organizational/budget impacts that are material to a reimbursement decision. However, MEAs should be the exception and not the norm, as indicated in Figure 1.

If HTA does not identify any concern that is material to the coverage decision, the three traditional approaches can be taken, they are to fund without any restrictions, to fund with certain restrictions (for example, context of use or subpopulation), or not to fund.

Early engagement between the manufacturer and the payer is needed to collaborate on the form and details of the MEA. There is a need for electronic medical records or data management systems to be in place to assess the data that are generated. Where necessary, there must be good research governance, including consideration of issues relating to patients, such as data protection and informed consent. Such agreements need to be time-limited with a pre-agreed schedule to evaluate whether the concerns or issues in question have been resolved, taking particular account of the need for robust monitoring data (8). When an agreement is made to manage uncertainty relating to clinical and/or costeffectiveness (CED), all stakeholders should be involved in developing clear protocols with well-defined research questions and definitions of which outcomes are to be measured and how these should be measured.

\section{DISCUSSION}

Decision makers at a variety of levels in the hierarchy of a healthcare system struggle to balance the encouragement of innovation and productivity, providing a fair return on investment, accessibility of patients to promising innovations in technology, affordability of healthcare services, and transparency in pricing. One possible solution to this conundrum is MEAs. However, although the linkage between reimbursement and a technology's actual performance, utilization, or budget impact in these agreements may seem attractive, there are obstacles to overcome before they can be implemented.

An editorial about AED (12) suggested that standard principles of accountability for reasonableness should be used including the four elements of legitimacy and fairness in decision making: (i) stakeholder involvement, (ii) transparency and openness to public dissemination of the basis of decision making, (iii) clear description of the basis for review and appeal, and (iv) assertive leadership, including 


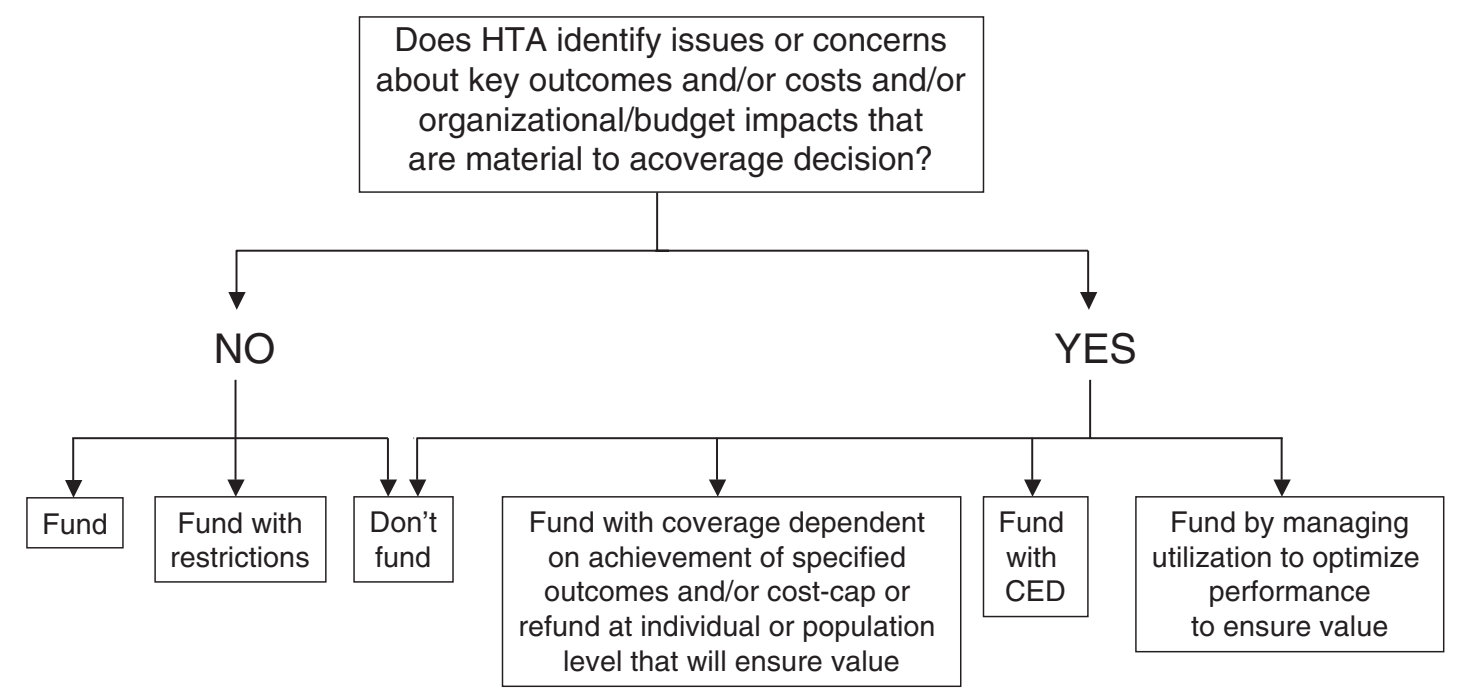

Figure 1. MEA decision tree based on HTA.

acceptance of accountability (6). All these elements are brought into sharp focus in the debate about CED, and we believe they apply to the wider arena of MEAs as well. In particular, the first two principles, of stakeholder involvement and transparency of decision making could be questioned in relation to MEAs. An MEA appears to be made in confidence between payer/providers and manufacturers. It is clear that there will be some confidential issues that require discussion, but as much information as possible should be put in the public domain. As a minimum, the final MEA should be clearly published and made available to all stakeholders. From the examples we have reviewed, it is difficult to ascertain whether patients and clinicians were involved in establishing the MEA or whether the risks associated with the agreement compared to an alternative course of action were discussed.

It is of note that there are few examples of MEAs for devices given the limited data available for devices at market launch and the importance of managing diffusion to ensure appropriate use.

It is particularly important to ensure that MEAs are not used when alternative approaches might be better. For example, there is a growing emphasis on the need for comparative effectiveness studies to inform evidence-based health policy making (17). A risk of MEAs would seem to be that these comparative trials in a real world setting are displaced by the nonrandomized, observational data that might arise from MEAs.

Overall, collaborative work is needed to improve the evidence that is available at the time a technology is marketed to clarify evidence requirements of both regulators and those responsible for reimbursement. This will require earlier engagement on technology development plans and better interaction among regulators and agencies to better link regulatory needs to payer/provider and HTA needs (7).

\section{POLICY IMPLICATIONS}

MEAs are being increasingly used to give access to innovative technologies, but they should only be used when traditional reimbursement is not deemed appropriate. When used, MEAs should take the form of a formal written agreement among stakeholders, clearly identifying the rationale for the agreement, aspects to be assessed, methods of review, and the criteria for ending the agreement. The benefits and risks associated with the agreement compared to alternative courses of action should be made clear to all stakeholders.

The principles of legitimacy and fairness in decision making should govern MEAs, with better involvement of all stakeholders (particularly clinicians and patients) in their development and greater transparency.

These agreements should be looked upon with caution and only used in certain situations as their sustainability is unclear and the effectiveness of these agreements in meeting their objectives has yet to be evaluated.

\section{SUPPLEMENTARY MATERIAL}

Supplementary Table 1

Supplementary Table 2

www.journals.cambridge.org/thc2011005

\section{CONTACT INFORMATION}

Marianne Klemp, $\mathrm{MD}, \quad \mathrm{PhD}$ (marianne.klemp@ kunnskapssenteret.no), Research Director, Norwegian Knowledge Centre for the Health Services, P.O. Box 7004 St., Olavsplass, N-0130, Oslo, Norway

Katrine B Frønsdal, PhD, MSc (kbf@nokc.no), Senior Researcher, Norwegian Knowledge Centre for the Health Services, P.O. Box 7004 St., Olavsplass, N-0130, Oslo, Norway 
Karen M. Facey, Hon MFPH, CStat, PhD, BSc (Hons) (k.facey@btinternet.com), Honorary Senior Research Fellow, Public Health, University of Glasgow, Woodlands Lodge, Buchanan Castle Estate, Drymen G63 0HX, United Kingdom

\section{CONFLICT OF INTEREST}

M Klemp and K Fronsdal report having received consulting fees from the HTAi Policy Forum for their institution (NOKC) that houses the scientific secretariat for the Policy Forum.

K Facey has received funding as a Member of the Board at NHS Forth Valley (UK), and for chairing HTAi Policy Forum in 2009-2010. She has received consultancy fees or travel funding from the National Institutes of Health Research, the EUnetHTA network, Guidelines International Network, HTA agencies, patient organisations, international pharmaceutical companies, and governmental departments. Her husband is a general practitioner in the UK.

\section{REFERENCES}

1. Adams CP, Brantner VV. Spending on new drug development. Health Econ. 2010;19:130-141.

2. Australian Government, Department of Health and Ageing. Pharmaceutical benefits scheme. http://www.pbs.gov. $\mathrm{au} / \mathrm{html} /$ industry/static/how_to_list_on_the_pbs/elements_of_ the_listing_process/guidelines_for_deeds_of_agreement (accessed June 2010).

3. Bell KJ, Irwig L, March LM, et al. Should response rules be used to decide continued subsidy of very expensive drugs? A checklist for decision makers. Pharmacoepidemiol Drug Saf. 2010;1:99-105.

4. Briggs A, Ritchie K, Fenwick E, Chalkidou K, Littlejohns P. Access with evidence development in the UK: Past experience, current initiatives and future potential. Pharmacoeconomics. 2010;28:163-170.

5. Carlson JJ, Sullivan SD, Garrison LP, Neumann PJ, Veenstraa DL. Linking payment to health outcomes: A taxonomy and examination of performance-based reimbursement schemes between healthcare payers and manufacturers. Health Policy. 2010;96:179-190.

6. Daniels N, Sabin JE. Accountability for reasonableness: An update. BMJ. 2008;337:a1850.

7. Eichler HG, Bloechl-Daum B, Abadie E, et al. Relative efficacy of drugs: An emerging issue between regulatory agencies and third-party payers. Nat Rev Drug Discov. 2010;9:277-291.

8. Frønsdal KB, Facey K, Klemp M, et al. Health technology assessment to optimize health technology utilization: Using implementation initiatives and monitoring processes. Int J Technol Assess Health Care. 2010;26:309-318.

9. Gormley GJ, Stoner E, Bruskewitz RC, et al. The effect of finasteridein men with benign prostatic hyperplasia. The Finasteride Study Group. N Engl J Med. 1992;327:1185-1191.

10. High Level Pharmaceutical Forum 2005-2008. Final conclusions and recommendations of the High Level Pharmaceutical Forum. http://ec.europa.eu/pharmaforum/docs/final_ conclusions_en.pdf (accessed March 2010).

11. Hutton J, Trueman P, Henshall C. Coverage with evidence development: An examination of conceptual and policy issues. Int J Technol Assess Health Care. 2007;2:425-435.

12. MacLeod S, Mitton C. We know accurately only when we know little. Pharmacoeconomics. 2010;28:1-3.

13. McCabe C, Stafinski T, Edlin R, Menon D, for and on behalf of the Banff AED. Summit. Access with evidence development schemes: A framework for description and evaluation. Pharmacoeconomics. 2010;28:1-10.

14. Mohr PE, Tunis SR. Access with evidence development: The US experience. Pharmacoeconomics. 2010;28:153-162.

15. Paul SM, Mytelka DS, Dunwiddie CT, et al. How to improve R\&D productivity: The pharmaceutical industry's grand challenge. Nat Rev Drug Discov. 2010;9:203-214.

16. Rosenfeld PJ, Brown DM, Heier JS, et al. MARINA Study Group. Ranibizumab for neovascular age-related macular degeneration. N Engl J Med. 2006;355:1419-1431.

17. Sox HC, Greenfield S. Comparative effectiveness research: A report from the Institute of Medicine. Ann. Intern Med. 2009;151:203-205.

18. Stafinski T, McCabe CJ, Menon D. Funding the unfundable: Mechanisms for managing uncertainty in decisions on the introduction of new and innovative technologies into healthcare systems. Pharmacoeconomics. 2010;28:1-29. 